\title{
Provision of contrasting ecosystem services by soil communities from different agricultural fields
}

\author{
Erik Verbruggen • E. Toby Kiers • \\ Patrick N. C. Bakelaar • Wilfred F. M. Röling • \\ Marcel G. A. van der Heijden
}

Received: 10 February 2011 / Accepted: 12 May 2011 / Published online: 14 June 2011

(C) The Author(s) 2011. This article is published with open access at Springerlink.com

\begin{abstract}
Several studies have shown that soil biotic communities from organically managed fields are more diverse and exhibit higher activity levels compared to conventionally managed fields. The impact of these different soil communities on plant productivity and the provision of soil ecosystem services are, however, still unclear. Here, we test the effects of soil inoculation from each of three organic and three conventional maize fields on maize productivity and nutrient loss during leaching events
\end{abstract}

Responsible Editor: Gerlinde de Deyn.

Electronic supplementary material The online version of this article (doi:10.1007/s11104-011-0828-5) contains supplementary material, which is available to authorized users.

E. Verbruggen · E. T. Kiers • P. N. C. Bakelaar

M. G. A. van der Heijden

Department of Ecological Science, Faculty of Earth and

Life Sciences, VU University Amsterdam,

Amsterdam, the Netherlands

E. Verbruggen

e-mail: erik.verbruggen@falw.vu.nl

E. T. Kiers

e-mail: toby.kiers@falw.vu.nl

P. N. C. Bakelaar

e-mail: pncbakelaar@hotmail.com

E. T. Kiers

Department of Plant, Soil and Insect Science,

University of Massachusetts at Amherst,

Amherst, MA, USA induced by simulated rain. In particular, we examine whether differences in productivity and nutrient loss are related to the abundance and species composition of arbuscular mycorrhizal (AM) fungi. We hypothesized that soil biota from organically managed fields would improve maize growth and reduce nutrient leaching significantly more than those from conventionally managed fields. In contrast to our hypothesis, we found that plant productivity was negatively affected by soil inoculation, and this
W. F. M. Röling

Molecular Cell Physiology, Faculty of Earth and Life Sciences, VU University Amsterdam,

Amsterdam, the Netherlands

e-mail: wilfred.roling@falw.vu.nl

M. G. A. van der Heijden

Ecological Farming Systems, Research Station ART, Agroscope Reckenholz Tänikon,

Zürich, Switzerland

M. G. A. van der Heijden $(\square)$

Plant-Microbe Interactions, Institute of Environmental

Biology, Faculty of Science, Utrecht University,

3508 TB Utrecht, the Netherlands

e-mail: marcel.vanderheijden@art.admin.ch 
effect was stronger with inoculum from organic fields. Plant productivity was inversely correlated with AMF abundance, suggesting that enhanced carbon allocation to AMF is at least in part responsible for plant growth reduction under our experimental conditions. However, soil inoculation did alter the ecological functioning of the system by reducing phosphorus leaching losses after simulated rain. Moreover, these leaching losses were lower with increased hyphal density and were related with abundance of particular AMF types, suggesting that abundance of AMF and their community composition may be useful indicators of phosphorus leaching losses. The results demonstrate that soil communities from different agricultural fields vary in their impact on plant productivity and nutrient leaching losses. The results further indicate that there is a potential tradeoff between positive effects of soil communities on sustainability and negative effects on crop productivity.

Keywords Arbuscular mycorrhizal fungi - Biomass production · Phosphorus leaching · Plant-soil feedback · Soil functioning $\cdot$ Sustainability

\section{Introduction}

Organic farming is often advocated as a means to increase species diversity in agro-ecosystems (Bengtsson et al. 2005; Crowder et al. 2010). Several studies have demonstrated that soil microbial communities of organically managed fields are more diverse and exhibit higher activity (e.g. microbial respiration and functional gene expression) levels compared to communities of conventionally managed arable fields (Mäder et al. 2002; Postma-Blaauw et al. 2010; Reeve et al. 2010; Verbruggen et al. 2010). How such differences in soil communities translate to differences in plant productivity and the provision of soil ecosystem services is unresolved. Studies performed in grasslands have shown that increased soil biodiversity can enhance above-ground diversity (De Deyn et al. 2004; Hooper et al. 2005; Wardle et al. 2004) and productivity (van der Heijden et al. 1998). However, large variation exists in responses of plants to soil communities, as has been highlighted in studies on the lasting effect after cessation of agricultural management on revegetation (Kulmatiski and Beard
2008; Kulmatiski et al. 2006) and in studies on plant-soil feedback (Casper and Castelli 2007). For instance, outcome and effect-size of plant-soil biotic interactions have been reported to vary from positive to negative with successional stage, soil nutrient levels, and plant species identity (Gustafson and Casper 2004; Kardol et al. 2006, 2007). Therefore, how soil communities selected under different management regimes affect plant production will also likely vary from positive to negative.

Soil microbial communities can likewise affect critically important ecosystem services, such as nutrient retention in soil. Nutrient leaching from agricultural fields has been identified as one of the major sources of global eutrophication (Bouwman et al. 2009; Carpenter et al. 1998), which is among the largest environmental problems faced today (Diaz and Rosenberg 2008; Tilman et al. 2001). Application of fertilizers to agricultural fields likewise represents a major cost to farmers, especially in light of the expected scarcity of phosphorus (Cordell et al. 2009). A reduction of leached nutrients has the potential to significantly reduce fertilizer-related costs (Goulding et al. 2008) and could enhance agricultural sustainability (Power 2010). Microbial community composition has been shown to affect the rate and severity of nutrient loss in agricultural soils (Gordon et al. 2008; Yang et al. 2008). Therefore, linking soil management regimes to the composition and performance of nutrient-mediating microbial biota is a crucial step forward in responding to the economic inefficiency and eutrophication arising from farm-level nutrient leaching.

A core group of soil organisms in regulating plant-soil interactions and nutrient fluxes are the arbuscular mycorrhizal fungi (AMF). These fungi are a ubiquitous class of microbial mutualists that colonize plant roots in natural and agricultural ecosystems. In this mutualism, the mycorrhizal fungal partner forms an obligate symbiosis with its host plant, exchanging nutrients from the soil for carbon from the host. Increasingly, the importance of AMF for agricultural sustainability is being recognized (Sanders 2010; Verbruggen and Kiers 2010). Via various attributes, such as nutrient acquisition (Johnson 2010; Smith and Read 2008), pathogen suppression (Lendzemo et al. 2005), herbivory protection (Bennett et al. 2009; Gange and West 1994) and improved water relations and 
soil structure (Augé 2001; Wilson et al. 2009), mycorrhizal fungi can benefit crop hosts and ecosystem sustainability. For example, recent studies have shown that AMF are fundamental in preventing nutrient loss in modelled grasslands after raininduced leaching events, resulting in an up to $60 \%$ reduction of phosphorus loss (Asghari et al. 2005; van der Heijden 2010). The ability of AMF to capture and retain nutrients also means that the mycorrhizal mutualism can promote tighter nutrient cycling (Moonen and Bàrberi 2008; Rillig 2004), although effects of AMF on plant growth can vary from positive to negative (Smith et al. 2009).

Our previous work has shown that AMF communities from agricultural fields on sandy soils (either managed organically or conventionally) differ greatly in composition and richness (Verbruggen et al. 2010), with an average AMF richness of organically managed fields nearly twice as high as conventional fields. This is confirmed by many studies suggesting that species composition, richness, and abundance is highly sensitivity to management regime (Gosling et al. 2010; Hijri et al. 2006; Johnson 1993; Oehl et al. 2010). However, whether AMF communities from organically managed fields differ functionally from communities of conventionally managed fields is an unknown but crucial question which we address in the current study.

Here we ask: 1) Are there differences in plant biomass production when crop plants (maize) are grown in the presence of soil microbial communities originating from organic or conventional agricultural fields? 2) Do microbial communities from these two management types differ in their ability to prevent phosphorus leaching? and 3) Do these functional attributes relate to AMF development (root and soil colonization) and abundance of particular AMF species? We answer these questions in two complimentary experiments in which soils from five organic and five conventional maize fields were tested for their effect on maize productivity and a subset of these for nutrient loss during leaching events induced by simulated rain. We then test whether differences in productivity and nutrient loss can be related to the abundance and species composition of AMF. Our ultimate aim is to determine the functional consequences of different agricultural regimes on soil biodiversity and community composition so we can better utilize microbial biota to enhance the sustainability of agro-ecosystems.

\section{Materials and methods}

Soil inocula and plant material

Soils from ten Dutch maize fields (five organically and five conventionally managed, referred to as 'Management types' in the following text) were collected in September 2007. Each field site (also referred to as 'field origin') is described in Table 1. Briefly, all organically managed sites had been converted at least 8 years ago, and had a crop rotation of predominantly maize, wheat, grass and grass-clover mixtures. Conventionally managed fields were all regularly treated with herbicide and mineral fertilizer and had been subject to lower crop rotation diversity, with an average frequency of maize being cropped in the previous 4 years of $62 \%$ (versus $43 \%$ in organic). All fields were on sandy textured soils and spatially intermixed (see Table 1 for coordinates, and Online Resource 1 for a map with field locations). Our earlier work in these fields has shown that AMF richness varies on maize hosts, ranging from two to nine AMF taxa, with the highest richness found in organically managed fields (Verbruggen et al. 2010).

Soil was sampled as follows: six cores (core length, $14.5 \mathrm{~cm}$; diameter, $6.5 \mathrm{~cm}$ ) were taken, evenly distributed within a hectare of a field, each adjacent ( $\pm 5 \mathrm{~cm}$ distance) to a standing plant. Care was taken not to include weeds in order to avoid effects of different host plants on soil communities. The cores were pooled, mixed and roots were cut to pieces of $1 \mathrm{~cm}$. The resulting mixture was air dried for 3 weeks. In parallel, soil was extracted with the same gauge adjacent to each root sample and subjected to chemical analysis by BLGG (Bedrijfslaboratorium voor Grond- en Gewasonderzoek; Oosterbeek, the Netherlands). The chemical measurements included: $\mathrm{pH}$, mineral nitrogen, organic matter content and plant available phosphate $\left(\mathrm{CaCl}_{2}\right.$ extraction). In general, organically management fields showed a slightly higher $\mathrm{pH}$ and slightly lower phosphate availability (Table 1). These soils were used to grow maize (Zea mays L. subvariety Lafortuna; KWS Middenmeer) in two experiments (1 and 2; see below).

\section{Experiment 1: Impact of field origin of inoculum} on maize productivity

The goal of this experiment was two-fold: first, to test whether soil inocula from organically managed fields 
Table 1 Chemical characteristics, approximate AMF species richness and colonization percentage of maize roots in fields where soil was collected as inoculum for the experiments. The coordinates of each field location are shown in the last two columns (latitude and longitude). Both species richness (AMF \#) and colonization (\%) present the average of two samplings, one at a plant age of 3 months and one at 5 months (as in Verbruggen et al. 2010). Soils indicated by an asterisk (*) were used for experiment $2 . \mathrm{O}=$ organic agricultural fields, $\mathrm{C}=$ conventional agricultural fields. Colonization percentages (\%) in the field did not differ significantly between organic and conventional fields

\begin{tabular}{|c|c|c|c|c|c|c|c|c|c|}
\hline Field origin & $\mathrm{C} / \mathrm{N}$ ratio & $\mathrm{P}(\mathrm{mg} / \mathrm{kg})$ & $\mathrm{pH}$ & $\mathrm{OM}$ & $\mathrm{N}(\mathrm{g} / \mathrm{kg})$ & AMF \# & $\%$ & Latitude & Longitude \\
\hline $\mathrm{O} 1 *$ & 14 & 10.8 & 5.4 & 2.9 & 1.19 & 9 & 34 & 52.22 & 5.66 \\
\hline $\mathrm{O} 2 *$ & 16 & 8.3 & 4.1 & 4.1 & 1.45 & 6 & 31 & 52.56 & 6.42 \\
\hline $\mathrm{O} 3 *$ & 12 & 10.0 & 5.3 & 4.1 & 2.01 & 3 & 26 & 52.18 & 6.88 \\
\hline $\mathrm{O} 4$ & 15 & 1.5 & 5.2 & 3.4 & 1.36 & 8 & 58 & 51.45 & 5.12 \\
\hline O5 & 10 & 6.7 & 5.7 & 2.8 & 1.64 & 7 & 45 & 51.65 & 5.21 \\
\hline Mean(se) & $13.4(1.1)$ & $7.5(1.6)$ & $5.1(0.3)$ & $3.5(0.3)$ & $1.53(0.14)$ & $6.5(1.0)$ & $38.5(5.6)$ & & \\
\hline $\mathrm{C} 1 *$ & 15 & 15.4 & 4.4 & 3.8 & 1.44 & 3 & 14 & 51.45 & 5.13 \\
\hline $\mathrm{C} 2 *$ & 17 & 9.0 & 5.5 & 2.6 & 0.91 & 6 & 27 & 52.57 & 6.45 \\
\hline $\mathrm{C} 3 *$ & 14 & 12.8 & 4.1 & 4.2 & 1.75 & 2 & 9 & 52.18 & 6.88 \\
\hline $\mathrm{C} 4$ & 16 & 7.7 & 4.7 & 2.8 & 1.00 & 4 & 25 & 52.22 & 5.74 \\
\hline $\mathrm{C} 5$ & 12 & 2.2 & 5.2 & 3.0 & 1.43 & 5 & 46 & 51.65 & 5.21 \\
\hline Mean(se) & $14.8(0.8)$ & $9.4(2.1)$ & $4.8(0.2)$ & $3.3(0.3)$ & $1.30(0.15)$ & $3.8(0.7)$ & $24(5.8)$ & & \\
\hline
\end{tabular}

differentially impacted maize productivity compared to soil inocula from conventionally managed fields. Second, we aimed to produce a more standardized (i.e. produced under uniform conditions) soil inoculum for experiment 2 . Three hundred gram of soil from each site was used as inoculum and added to a $2.7 \mathrm{~kg}$ sterilized mixture of $50 \%$ organic agricultural soil (derived from another field than used in these experiments as inoculum; $4.2 \mathrm{mg} / \mathrm{kg} \mathrm{P}, 121 \mathrm{mg} / \mathrm{kg} \mathrm{K}$ (both $\mathrm{CaCl}_{2^{-}}$ extracted; plant available) and $2.1 \mathrm{~g} / \mathrm{kg} \mathrm{N}$ (N-elementary) pH: 5.1), and 50\% nutrient-poor sand (as used in: Scheublin et al. 2007). This final 50:50 soil mixture contained roughly half of the nutrient levels of the agricultural soil. One maize seedling was grown per pot (pot width $19 \mathrm{~cm}$ and $18.5 \mathrm{~cm}$ depth), with six replicate pots per soil inoculum (10 field origins $\times 6$ replicates). There were two additional inoculum treatments. The first was a control inoculum, consisting of a composite of all ten soil-inocula, combined and then sterilized. The second was an inoculum of one specific AMF isolate, Glomus intraradices Schenck \& Smith (BEG21 - see Scheublin et al. 2007 for propagation details). The inclusion of this treatment enabled us to compare effects of field soil inoculation with one wellknown and specific AMF inoculum. The plants were grown in the greenhouse with $16 \mathrm{~h} \mathrm{light} / 8 \mathrm{~h}$ dark cycles and watered to $15 \%$ water content twice a week.
After 12 weeks, watering was stopped to stimulate sporulation of AMF. Four weeks later, plants were harvested and aboveground biomass was determined. Soil was stored at $4^{\circ} \mathrm{C}$ for 6 months prior to use in experiment 2. AMF colonization of roots was determined by staining with trypan blue and quantification with the magnified intersection method (McGonigle et al. 1990) using 100 intersections per sample.

Experiment 2: Analysis of ecological functioning of a subset of soils

The goal of experiment two was to test for nutrient retention effects of microbial communities and AMF density and richness. Six of the ten different inocula produced in experiment 1 (three originating from organically managed fields and three from conventionally managed fields) were selected for experiment 2. These six inocula represented the full spectrum of AMF colonization variation from within the ten different soils used in experiment 1 (Fig. 1 and Table 1 for details). Use of inocula produced in experiment 1 , under standardized climate and identical maize variety, allowed us to minimize differences in field conditions (e.g. soil fertility, plant growth stage) unrelated to soil communities. 
Fig. 1 Plant biomass (abovegroud dry-weight) and AMF root colonization percentage of maize with soil inoculum from five organic (O1-O5) and five conventional (C1-C5) fields (Experiment 1). Control pots received sterilized soil inoculum (St.) or soil inoculum with one specific AMF (AMF). Colors indicate: black, organic; grey, conventional; white, controls. Error bars indicate standard error
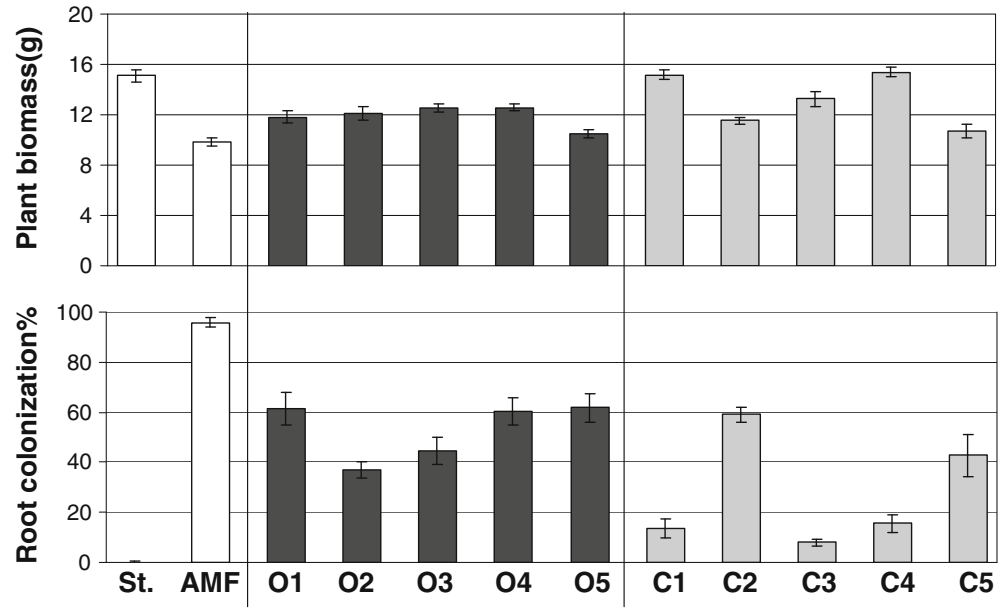

A bulk background soil mixture was created consisting of $15 \%$ sterilized agricultural soil (see Experiment 1 above for nutrient content) and 85\% nutrient poor sand into pots of $12 \mathrm{~cm}$ width and $11.5 \mathrm{~cm}$ depth. This final bulk soil mixture contained $1.1 \mathrm{mg} / \mathrm{kg} \mathrm{P}, 15 \mathrm{mg} / \mathrm{kg} \mathrm{K}$ (both $\mathrm{CaCl}_{2}$ extractable), $39.3 \mathrm{mg} / \mathrm{kg} \mathrm{P}$ (ammonium lactate acidic extractable), and $250 \mathrm{mg} / \mathrm{kg} \mathrm{N}$ (N-elementary) $\mathrm{pH}=7.4)$. For each inoculum source, three inoculum densities $(0 \%, 4 \%$ and $12 \%$ of total soil weight) were used to determine if inoculum amount affected functional characteristics. Treatments with $0 \%$ or $4 \%$ inoculum received respectively $12 \%$ and $8 \%$ sterilized inoculum to ensure that the same amount of soil was added to each pot. This resulted in a total of combination of 6 soil inocula $\times 3$ densities $\times 6$ replicates $=108$ pots. The two different inoculum densities (4\% and $12 \%$ ) were used to further assess the effect of inoculum density on plant growth and nutrient leaching (see below). To all treatments, $10 \mathrm{ml}$ of a microbial wash (Koide and Li 1989) was added composed of a mixed filtrate $(<10 \mu \mathrm{m})$ of all combined inocula used for this experiment (100 g per inoculum). This procedure standardizes the non-fungal microbial community among treatments, as well as for fungi with spores smaller than $10 \mu \mathrm{m}$. Equally sized, 1 week old maize seedlings were planted in soils and a one time addition of $10 \mathrm{ml} \mathrm{1/4} \mathrm{P} \mathrm{Hoagland}$ solution (Hoagland and Arnon 1950) was added. Plants were grown for 10 weeks under greenhouse conditions, as above, and watered three times a week with demineralised water to sustain soil moisture of $15 \%$.

Leaching measurements

One day before harvest, $10 \mathrm{ml}$ of $1 / 2 \mathrm{P}$ Hoagland solution (containing $0.95 \mathrm{mg}$ phosphate) was added to all pots. Following the harvesting of above ground plant material, the pots were placed in a water drip setup (Knacker et al. 2004) containing $500 \mathrm{ml}$ of tap water. Water was dripped into the pots for $1 \mathrm{~h}$. The resulting leachate was collected in a bottle connected to the pot with a tube to prevent evaporation and stored at $-20^{\circ} \mathrm{C}$ until further analysis. Upon thawing, leachate was filtered (pore size $=0.45 \mu \mathrm{m}$, Whatman FP30, Germany) and analysed colorimetrically for phosphate concentration with a continuous flow autoanalyser (SKALAR-SA-40; Skalar Analytical B. V., Breda, The Netherlands).

Plant and fungal measurements

The aboveground plant material was dried and weighted for biomass determination (hereafter: plant biomass). A subset of the roots was stained with tryphan blue to determine intraradical hyphal colonization-percentage using the magnified intersection method (McGonigle et al. 1990). Another subset of roots was freeze-dried for molecular analysis. For each replicate, a random subset of soil was taken and freeze-dried to obtain $70 \mathrm{~g}$ of dry weight soil for measurement of extraradical hyphal length density 
(hereafter: extraradical colonization), following the technique of Jakobsen et al. (1992).

In experiment 2 , AMF community composition in maize roots was determined using molecular tools. Detailed information on the molecular methods is given in Verbruggen et al.(2010). In brief: DNA was extracted from a subsample of replicates (four out of six randomly assigned replicates for each treatment) with the DNeasy Plant Mini Kit (Qiagen, Hilden, Germany) and extraction was checked on an agarose gel to confirm successful DNA isolation. One microliter $10 \times$ diluted extract was used as template in a nested PCR with primers LR1 and FLR2 (Trouvelot et al. 1999; van Tuinen et al. 1998) and, subsequently, labelled primers (name-label) FLR36FAM and FLR4-VIC (Gollotte et al. 2004) targeting the AMF large subunit rRNA gene. The obtained product was digested with restriction enzyme TaqI to obtain T-RFLP (Terminal Restriction Fragment Length Polymorphism) patterns of AMF colonizing the roots. Because T-RFLP has been shown to be semi-quantitative (Hartmann and Widmer 2008), the relative abundance of T-RFs was used for all analyses regarding AMF identity. More information about designation of AMF-types to T-RFs can be found in Online Resource 2.

\section{Statistical analysis}

For experiment one, plant biomass and intraradical colonization were compared with the field origin of the inoculum as a factor in a one-way ANOVA and in subsequent Tukey's post-hoc analysis. To test for effects of "management type" (inocula from organic vs. conventional fields) two nested ANOVAs were performed including only field-inoculated treatments, i.e. (1) all ten inocula in experiment 1 and (2) all $4 \%$ and $12 \%$ inoculum densities in experiment 2 . "Management type" was analysed as a fixed factor with field origin of the inoculums as a random factor nested in "Management type". This was done for dependent variables "biomass" and "intraradical colonization" in experiment 1 and 2, and also for "leached P", and "extraradical colonization" in experiment 2. Due to differences in volume of leachate collected, we multiplied $\mathrm{P}$ concentration by volume to give total P leached, which was used for all analyses. Leached $\mathrm{P}$ was rank-transformed to meet assumptions for the analysis. The effect of "inoculum density"
$(0 \%, 4 \%$ and $12 \%)$ on "amount of leached P" and "biomass" was compared with a one-way ANOVA and Tukey's b post-hoc test. Intraradical colonization (experiment 1 and 2) and extraradical colonization (experiment 2) were compared to plant biomass using Pearson correlations.

For intraradical colonization-percentage, additional tests were performed to estimate response to an increase of inoculum density. At lower infectivity, colonization is expected to increase approximately linearly and even off towards an asymptote with inoculum density (Liu and Luo 1994). Therefore, if the increases of colonization with inoculum density differ strongly between organically and conventionally derived inocula, this is an indication that potential effects are caused by either limitation or saturation of AMF propagules and not caused by differences other than abundance. The increase of colonization was determined by dividing the average colonization percentage at $12 \%$ inoculum density by that at $4 \%$ inoculum density for each inoculum source separately.

In order to test whether relative abundances of each AMF-type (as measured molecularly) were different between soil origins of the inocula, they were compared with a Kruskal-Wallis test. Also, we tested whether relative abundances were correlated with plant biomass, extraradical colonization and leaching of phosphorus using Spearman's rankcorrelation, and $P$ values were corrected for multiple testing. All statistical tests were performed using SPSS version 17.0.

\section{Results}

Experiment 1: Impact of soil inoculum on maize productivity

Contrary to expectations, maize biomass was significantly lower compared to the sterilized inoculum treatment (in nine out of 11 of the inoculated soils: $P<0.05$, Fig. 1). Plant biomass varied significantly between inocula (Nested ANOVA; field origin of inoculum: $F=13.51 ; P<0.01)$, although there was no main effect of organic or conventional management (Nested ANOVA: Org vs. Con: $F=1.66 ; P=0.23$ ). Plants inoculated with the AMF culture (Glomus intraradices) had the lowest overall plant biomass. 
All plants with unsterilized inoculum treatments were colonized by AMF. Colonization varied greatly between inocula (ranging from $8 \%$ to $62 \%$ ), with a marginally significant higher colonization for organically than conventionally managed fields (Nested ANOVA: Org vs. Con: $F=4.83 ; P=0.059$; field origin of inoculum: $F=12.17 ; P<0.01$ ). Plants inoculated with the single control AMF (Glomus intraradices) had the highest root colonization levels. Plant biomass and AMF root colonization levels were negatively correlated when all data were included in the analysis (Fig. 2a), and likewise when the non mycorrhizal (sterilized) treatment was removed from analysis $\left(R^{2}=0.43 ; P<0.001 ; N=66\right)$.
Fig. 2 Relationship between aboveground biomass of maize and mycorrhizal colonization of roots, in a experiment 1 and $\mathbf{b}$ experiment 2. For experiment 2 the plant biomass is also plotted against soil instead of root colonization (c). Treatments are indicated as before; $\mathrm{O} 1-\mathrm{O} 5=$ organic, $\mathrm{C} 1-\mathrm{C} 5=$ conventional, St. $=$ sterilized inoculum, and $\mathrm{AMF}=$ pure culture inoculum. Correlations were highly significant for experiment $1\left(R^{2}=0.49\right.$, $P<0.001, N=72)$ and experiment 2 (root colonization: $R^{2}=0.56, P<0.001, N=108$; soil colonization: $R^{2}=0.64$, $P<0.001, N=108$ )
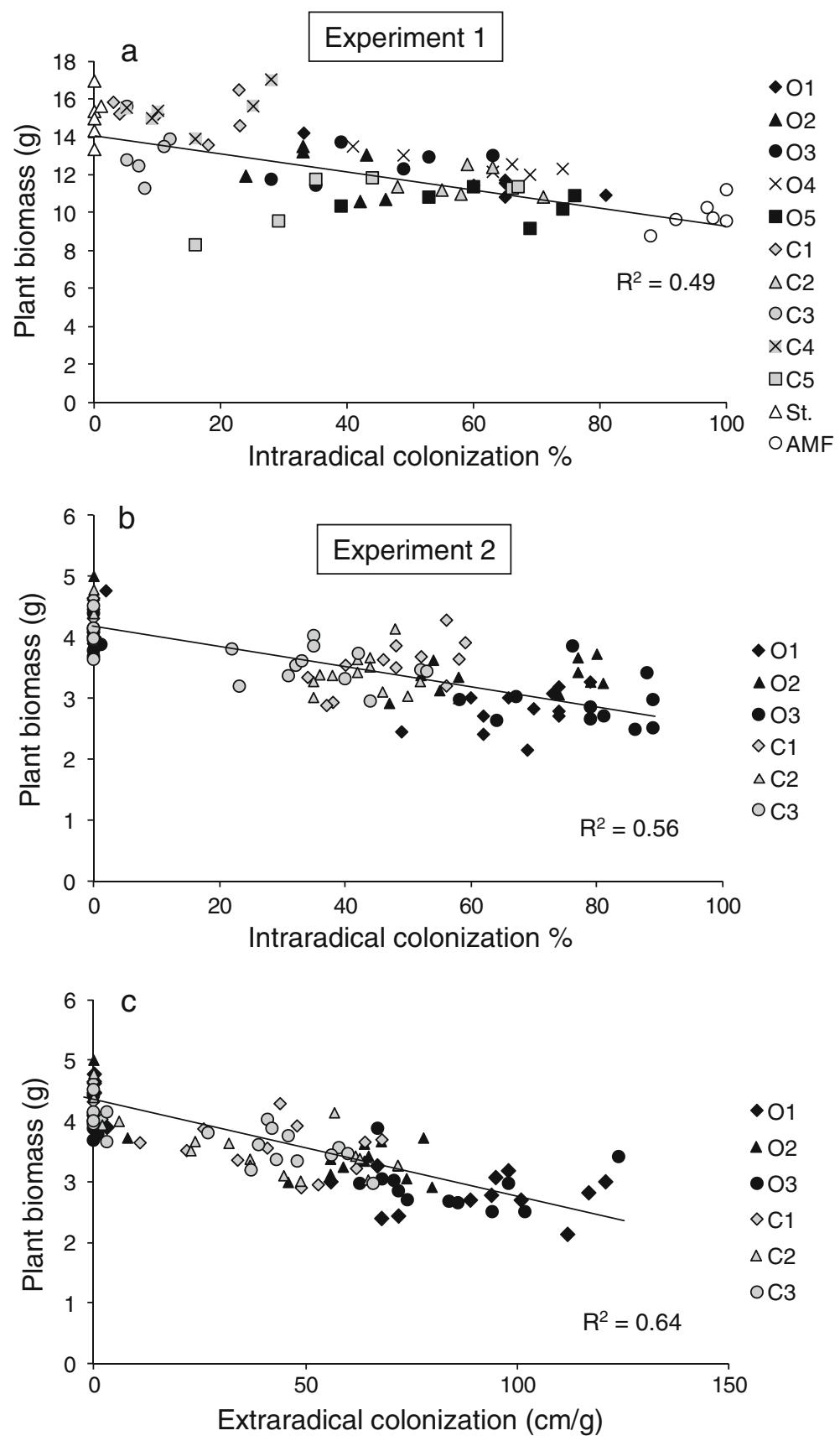
Experiment 2: Impact of soil inoculation on maize productivity and nutrient leaching

using a subset of soils

For the six soils in the second experiment inoculation also significantly reduced the aboveground dry weight of maize plants $(F=61.56 ; P<0.01$; Post-hoc: $0 \% \mathrm{a}, 4 \% \mathrm{~b}, 12 \% \mathrm{~b})$. The negative effect of soil inoculation on plant biomass varied greatly across fields (Fig. 2) and, in contrast with experiment 1, biomass of plants inoculated with soil from conventional management was significantly higher than those from organic management (Table 2; Fig. 3). There was no effect of increasing the inoculum density from $4 \%$ to $12 \%$ (Fig. 3). However, plant biomass across densities was strongly negatively correlated with colonization percentages (Fig. 2).

In agreement with results from experiment $1, \mathrm{AMF}$ root and soil colonization was significantly lower in experiments receiving an inoculum from conventional fields than from organic fields (Table 2). Average root colonization rates differed from $27 \%( \pm 5.8$ S.E. $)$ in conventional to $46 \%$ ( \pm 4.2 S.E.) in organic soils. Both root and soil colonization increased with increasing inoculum density, both for organic and conventional soils (Fig. 3). AMF colonization increased similarly with inoculum density for both management types, with increases ranging from factors of 1.11 to 1.44 , and 1.06 to 1.48 in organic and conventional derived inocula, respectively. No AMF was found in nonmycorrhizal controls (controls; Figs. 2 and 3), which indicates successful sterilization techniques.
Soil inoculation had a significant effect on total $\mathrm{P}$ leached. Densities of $4 \%$ and $12 \%$ inoculum leached less P than $0 \%$ inoculum treatments $(F=4.53 ; P=0.013$; posthoc: $0 \% \mathrm{a}, 4 \% \mathrm{~b}, 12 \% \mathrm{~b})$. For the non-AMF controls (inoculum density $=0 \%$ ), there was no difference in amount of $\mathrm{P}$ leached across field origins $(F=0.349$; $P=0.879$ ), suggesting that $\mathrm{P}$ leaching values are likely attributable to soil biota. There was a large amount of variation among the field sites tested. In some soils (e.g. soil O2, O3, C1 \& C3) P leaching was approximately the same in inoculated and non-inoculated soils, while in other soils, leaching losses in inoculated soils were significantly lower than controls (soil O1: $F=6.71$; $P<0.01$, soil C2: $F=3.80 ; P<0.05$; Fig. 3 ). There was a significant negative correlation between extraradical colonization and the amount of total $\mathrm{P}$ leached ( $R=-0.37, P<0.001, N=108$ ), and likewise when the sterilized inoculum treatments were removed from analysis $(R=-0.34, P<0.01 N=72)$ indicating that AMF abundance influences nutrient leaching.

T-RFLP patterns were dominated by a few $(\sim 3-4)$ AMF-types across samples (Table 3, Online Resource 3). This indicates a much lower richness in pots than in the field (range 2-9; see Table 1). AMF richness of maize plants in the fields was not correlated with AMF richness of the maize plants in this experiment $\left(R^{2}=0.38, P=0.11\right)$. Therefore it was not possible to use soil inocula from the field as a means to construct an AMF diversity gradient. However, AMF community composition in pots did differ between soil origins (six different soils) for each of the AMF types (Glomus Ab2: $\chi^{2}=36.7, P<0.01$; Glomus $\mathrm{D}: \chi^{2}=32.7, P<0.01$;
Table 2 ANOVA of the treatments with live inoculum with two factors: management type (organic versus conventional management) and nested in this factor "field origin of the inoculum" (field origin), to distinguish variance among fields and among management types. Five dependent variables were separately tested: shoot biomass, the amount of $\mathrm{P}$ leached, intraradical, and extraradical colonization

${ }^{*} P<0.05,{ }^{* *} P<0.01$

\begin{tabular}{|c|c|c|c|c|}
\hline & & df & $F$ & $p$ \\
\hline \multirow[t]{3}{*}{ Plant biomass } & Management type & 1 & 8.79 & $*$ \\
\hline & Field origin (management type) & 4 & 4.06 & $* *$ \\
\hline & Error & 66 & & \\
\hline \multirow[t]{3}{*}{ Total P leached } & Management type & 1 & 2.45 & \\
\hline & Field origin (management type) & 4 & 4.37 & $* *$ \\
\hline & Error & 66 & & \\
\hline \multirow[t]{3}{*}{ Intraradical colonization } & Management type & 1 & 36.25 & ** \\
\hline & Field origin (management type) & 4 & 4.13 & $* *$ \\
\hline & Error & 66 & & \\
\hline \multirow[t]{3}{*}{ Extraradical colonization } & Management type & 1 & 19.20 & $*$ \\
\hline & Field origin (management type) & 4 & 4.29 & $* *$ \\
\hline & Error & 66 & & \\
\hline
\end{tabular}


Glomus A4: $\chi^{2}=23.2, P<0.01 ;$ Glomus B1: $\chi^{2}=34.8$, $P<0.01$; Table 3, Online Resource 3).

Correlations were performed in order to assess whether the type of AMF colonizing the roots was related to maize biomass or P leaching (Table 3). Spearman's $\rho$ correlation between AMF type abundance and several variables (extraradical colonization, $\mathrm{P}$ leaching and plant biomass) showed that one AMF type (Glomus group Ab2; putative member of the $G$. intraradices clade according to the phylogenetic analysis presented in Verbruggen et al. 2010) was positively correlated with extraradical colonization and negatively with plant biomass and $\mathrm{P}$ leaching. This result suggests that plants are smaller and there is less P-loss through leaching when this AMF type is abundant. In contrast, plants in pots dominated by Glomus B are larger, with less soil colonization and more P leaching losses (Fig. 4).
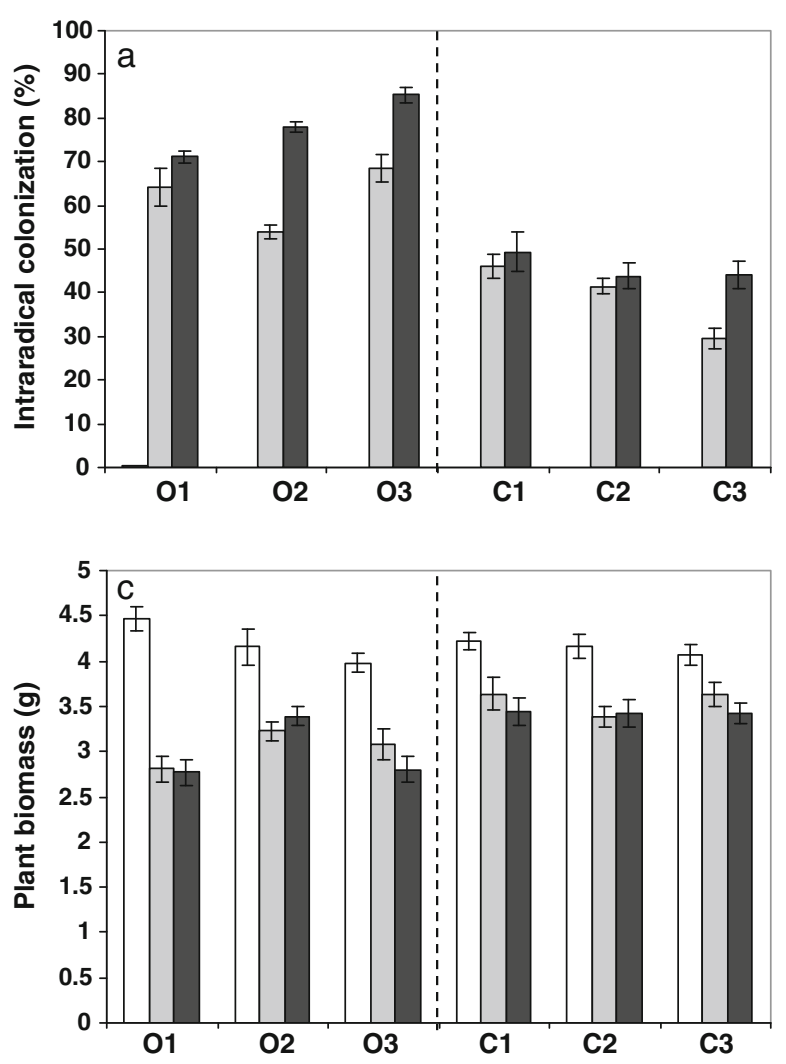

Fig. 3 Effect of management type and origin of soil inoculum in experiment 2 on average values ( \pm standard errors) for a intraradical (root) colonization, b extraradical (soil) colonization, $\mathbf{c}$ aboveground plant biomass production, and $\mathbf{d}$ amount of

\section{Discussion}

In our experiments, the goal was to assess the functioning of soil biotic communities independently of the immediate environmental context, and thus focus on differences that persist after propagation under common conditions. This was achieved by using a standard soil medium, and performing two sequential experiments, with the aim of removing any field-imposed differences, such as nutrient levels, $\mathrm{pH}$ or adverse chemical compounds. Using this approach, we demonstrate that maize plants grown in the presence of soil biota exhibit significantly reduced phosphorus leaching, compared to controls with only microbial soil washings. The provision of what can be regarded as an "ecosystem service", reduced leaching of phosphorus, was accompanied by a potential cost - a reduction in plant biomass production. This suggests that
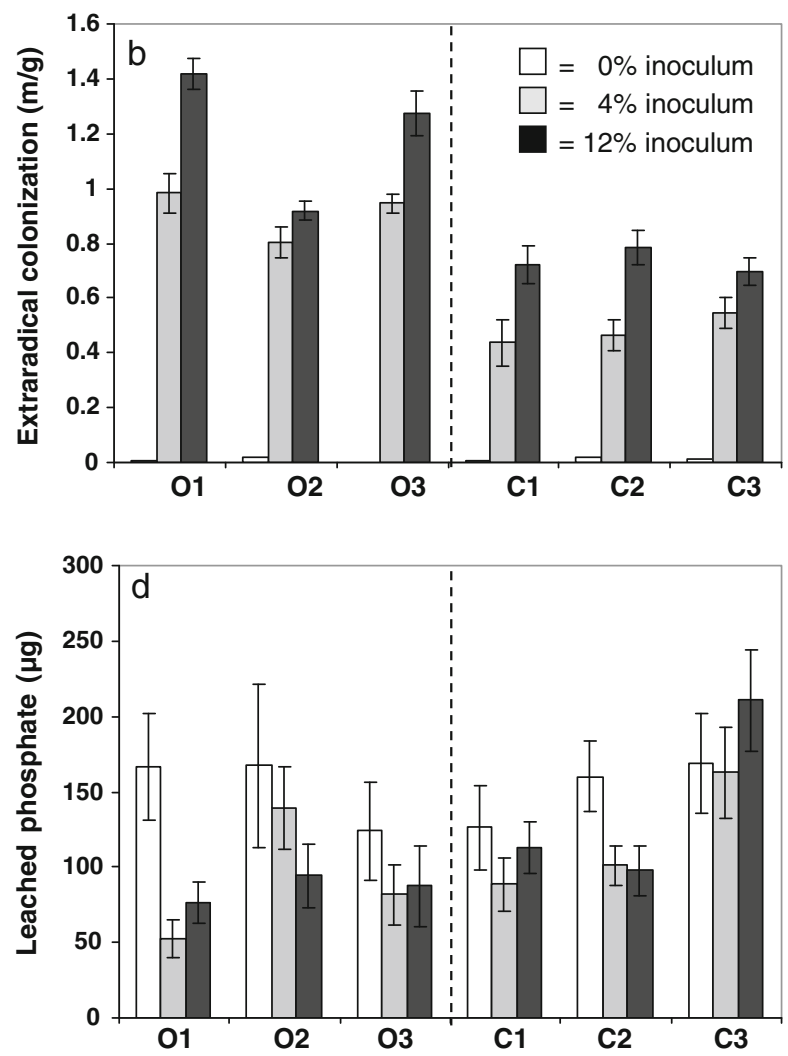

P leached. $\mathrm{O} 1-\mathrm{O} 3$ = inoculum derived from three organically managed fields, $\mathrm{C} 1-\mathrm{C} 3$ = inoculum derived from conventionally managed fields. Bar colours indicate inoculum densities as indicated in the upper right 
Table 3 Relative abundance of four AMF types (expressed as percentage of total) in maize roots grown for 3 months in pots inoculated with organic $(\mathrm{O} 1-\mathrm{O} 3)$ or conventional inoculums at two inoculums densities ( $4 \%$ and $12 \%$ ). The relative abundance is estimated based on the mean relative peak height of TRFs (see Methods). Only reverse fragments shown (length in basepairs in first row), as forward and reverse fragments show highly similar percentages. Bottom of table shows Spearman's rank correlations with extraradical colonization (hld), P leaching (P leach) and plant biomass (biomass) with each of the AMF-types across all non-sterilized inoculum treatments

\begin{tabular}{|c|c|c|c|c|c|c|c|c|c|}
\hline & & \multicolumn{2}{|c|}{45 Glomus Ab2 } & \multicolumn{2}{|c|}{70 Glomus D } & \multicolumn{2}{|c|}{185 Glomus A4 } & \multicolumn{2}{|c|}{212 Glomus B1 } \\
\hline & & Mean & SE & Mean & SE & Mean & SE & Mean & SE \\
\hline \multirow[t]{2}{*}{$\mathrm{O} 1$} & 4 & 69.0 & 12.1 & 0.0 & 0.0 & 14.9 & 5.0 & 16.1 & 5.9 \\
\hline & 12 & 69.0 & 3.8 & 0.0 & 0.0 & 11.9 & 2.0 & 19.1 & 3.2 \\
\hline \multirow[t]{2}{*}{$\mathrm{O} 2$} & 4 & 13.3 & 12.8 & 44.2 & 6.7 & 1.1 & 1.1 & 41.4 & 8.9 \\
\hline & 12 & 5.5 & 3.2 & 56.5 & 3.9 & 2.0 & 1.1 & 36.0 & 6.8 \\
\hline \multirow[t]{2}{*}{$\mathrm{O} 3$} & 4 & 86.5 & 5.4 & 1.5 & 1.5 & 1.6 & 1.0 & 10.5 & 3.5 \\
\hline & 12 & 86.6 & 2.1 & 0.0 & 0.0 & 4.7 & 2.6 & 8.7 & 2.0 \\
\hline \multirow[t]{2}{*}{$\mathrm{C} 1$} & 4 & 81.4 & 6.8 & 6.4 & 2.2 & 0.8 & 0.5 & 11.4 & 4.7 \\
\hline & 12 & 69.9 & 2.6 & 3.8 & 1.3 & 1.1 & 0.7 & 25.2 & 1.3 \\
\hline \multirow[t]{2}{*}{$\mathrm{C} 2$} & 4 & 8.2 & 4.4 & 8.7 & 8.7 & 20.7 & 9.8 & 62.4 & 5.1 \\
\hline & 12 & 26.1 & 3.1 & 0.0 & 0.0 & 18.8 & 1.7 & 55.1 & 2.4 \\
\hline \multirow[t]{2}{*}{$\mathrm{C} 3$} & 4 & 4.2 & 2.8 & 16.5 & 11.2 & 7.5 & 6.6 & 71.8 & 9.5 \\
\hline & 12 & 4.9 & 2.2 & 37.6 & 11.9 & 2.9 & 0.5 & 54.7 & 13.8 \\
\hline hld & & $0.368^{*}$ & & -0.323 & & 0.139 & & $-0.419^{*}$ & \\
\hline P leach & & $-0.355^{*}$ & & $0.480 * *$ & & -0.084 & & $0.360 *$ & \\
\hline biomass & & $-0.405^{*}$ & & 0.307 & & -0.083 & & $0.433^{* *}$ & \\
\hline
\end{tabular}

certain plant/soil-biotic combinations may potentially result in a negative effect on plant production while having a positive effect on ecosystem sustainability.

Reduced aboveground biomass (i.e. plant productivity) and reduced leaching losses were accompanied by a higher AM fungal density, suggesting a shift in biomass allocation from aboveground to fungal symbionts is responsible for those effects. Higher activity and abundance of microorganisms in organically managed fields has previously been reported (Mäder et al. 2002; Reeve et al. 2010; van Diepeningen et al. 2006). In our system, differences in AMF abundances (e.g. colonization patterns) persisted even after a generation of propagating the soil communities under standardized greenhouse conditions.

We hypothesized that soil biota from organically managed fields would improve maize growth and reduce nutrient leaching significantly more than those from conventionally managed fields. In contrast to our hypothesis, we did not observe that soil communities from organically managed fields enhanced maize growth. Instead soil inoculation reduced maize growth, probably due to enhanced AMF abundance (see below). Moreover, there was large variation among field sites, irrespective of management type. Phosphorus leaching varied greatly within management types, and soil communities reduced maize biomass in all the treatments with organic soil inoculums and in three out of five treatments with conventional soil inoculums (for experiment 1). This suggests that management type per se is not the overruling factor in determining how soil communities influence agro-ecosystem services, but that responses are field site specific. Therefore, whether organic management can potentially reduce phosphorus leaching by enhanced soil biological functioning, remains to be studied further and more field sites need to be included in order to make firm conclusions.

Interestingly, $\mathrm{P}$ leaching and plant productivity correlated with the abundance of specific AMF types (Table 3, Fig. 4). This finding is important because it suggests that different AMF types differ in ecosystem services provision (Kiers et al. 2002; Powell et al. 2009; Verbruggen and Kiers 2010). Moreover, this finding also indicates, when extrapolated to the field, 

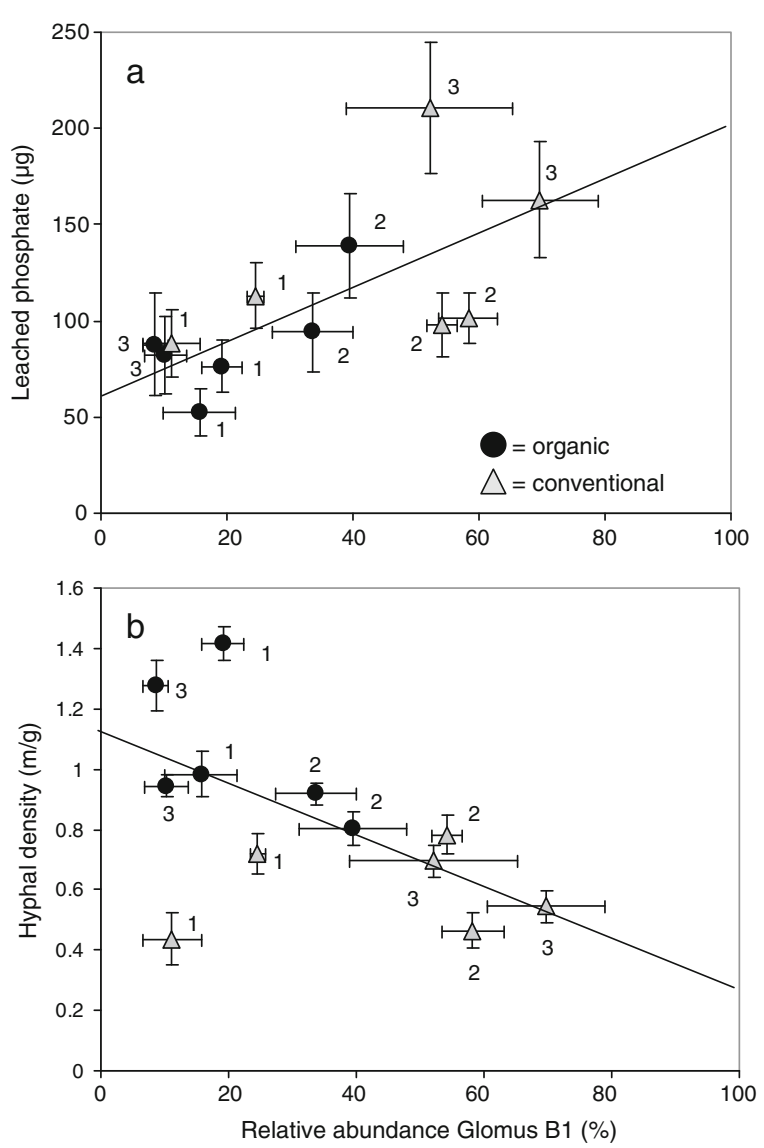

Fig. 4 Relationship between relative abundance ( \pm se) of Glomus B1 and a leaching of P, and $\mathbf{b}$ extraradical colonization in the samples. Averages are given for treatments with organic (grey triangles) or conventional (black circles). The three different field origins per management type are identified by numbers (1-3 and $\mathrm{C} 1-\mathrm{C} 3$ ). $4 \%$ and $12 \%$ inoculum density are both plotted simultaneously yielding two means for each field origin of inoculum

that differences or changes in AMF communities (e.g. caused by agricultural management regime) can alter the functioning of those systems. However, caution should be taken in translating our greenhouse experimental set-up to field situations.

Our observation that several AMF types present in the field soil inoculum did not colonize the maize plants under our experimental conditions, further emphasizes that care needs to be taken when extrapolating our results to field conditions. For instance, in contrast to the field situation where AMF richness varied between two and nine AMFtypes depending on the field site investigated (Table 1), three to four putative AMF types were present in each treatment. Clearly, greenhouse experiments select for AMF better capable of growing under these restricted conditions (e.g. Sykorova et al. 2007) and references therein). Interestingly, maize plants inoculated with inoculum from the site where we detected only two AMF types, contained four AMF types, showing that rare and undetected AMF types might become more abundant under favourable conditions. Nevertheless, relative abundance of AMF-types differed among treatments and specific AMF types correlated strongly with biomass production, soil colonization and leaching of phosphate (Table 3). This suggests that even this smaller subset of the AMF community exhibits traits that can be linked to specific ecosystem services.

Clearly soil biota other than AMF could have influenced our results. However, the inclusion of a standardized soil microbial filtrate to all treatments and the tight correlation between plant biomass and AMF abundance in both experiments (Fig. 2), point to AMF, specifically, as an important factor in explaining plant biomass differences. Furthermore, the fact that a cultured inoculum of Glomus intraradices AMF showed similar biomass trends supports the finding that our plant biomass reduction was caused by AMF, not other soil microbes. Negative effects of AMF on plants have been attributed to various attributes including "unresponsive" plant genotypes (Sawers et al. 2008), nutrient levels at which AMF are not beneficial (Hoeksema et al. 2010), or pot size causing limitations on fungal growth (Zhu et al. 2003). The fact that the cultured inoculum of Glomus intraradices we used in this experiment, stimulated plant growth in several other experiments with different plant species and soil types (Scheublin et al. 2007; van der Heijden et al. 2006) suggests that under our experimental conditions, AMF were not beneficial for stimulating plant productivity.

\section{Conclusions}

Our results indicate that soil communities can have contrasting effects on the provision of soil ecosystem services relevant to agricultural systems. Positive effect on one ecosystem service (reduced P leaching) may be linked with negative effects on another ecosystem service (crop production). Our findings also indicate that AMF density and the species composition of AMF communities can play an important role in explaining 
leaching and maize productivity. Future research should further explore how changes to soil biota, as a result of agricultural practices, will feedback to soil ecosystem service provision in agricultural systems.

Acknowledgments This research was funded by the Netherlands Organization for Scientific Research (ERGO grant 838.06.021 awarded to M.G.A.vd H.). E.T.K was funded by a Veni grant awarded by the Netherlands Organisation for Scientific Research and by the United States Department of Agriculture (USDA NRI 2008-02346). We would like to thank Bram Conijn for help in the first experiment.

Open Access This article is distributed under the terms of the Creative Commons Attribution Noncommercial License which permits any noncommercial use, distribution, and reproduction in any medium, provided the original author(s) and source are credited.

\section{References}

Asghari HR, Chittleborough DJ, Smith FA, Smith SE (2005) Influence of arbuscular mycorrhizal (AM) symbiosis on phosphorus leaching through soil cores. Plant Soil 275:181-193

Augé RM (2001) Water relations, drought and vesiculararbuscular mycorrhizal symbiosis. Mycorrhiza 11:3-42

Bengtsson J, Ahnstrom J, Weibull AC (2005) The effects of organic agriculture on biodiversity and abundance: a metaanalysis. J Appl Ecol 42:261-269

Bennett AE, Bever JD, Bowers MD (2009) Arbuscular mycorrhizal fungal species suppress inducible plant responses and alter defensive strategies following herbivory. Oecologia 160:771-779

Bouwman AF, Beusen AHW, Billen G (2009) Human alteration of the global nitrogen and phosphorus soil balances for the period 1970-2050. Glob Biogeochem Cycles 23:16

Carpenter SR, Caraco NF, Correll DL, Howarth RW, Sharpley AN, Smith VH (1998) Nonpoint pollution of surface waters with phosphorus and nitrogen. Ecol Appl 8:559-568

Casper BB, Castelli JP (2007) Evaluating plant-soil feedback together with competition in a serpentine grassland. Ecol Lett 10:394-400

Cordell D, Drangert JO, White S (2009) The story of phosphorus: global food security and food for thought. Glob Environ Change 19:292-305

Crowder DW, Northfield TD, Strand MR, Snyder WE (2010) Organic agriculture promotes evenness and natural pest control. Nature 466:109-112

De Deyn GB, Raaijmakers CE, Van der Putten WH (2004) Plant community development is affected by nutrients and soil biota. J Ecol 92:824-834

Diaz RJ, Rosenberg R (2008) Spreading dead zones and consequences for marine ecosystems. Science 321:926-929

Gange AC, West HM (1994) Interactions between Arbuscular Mycorrhizal Fungi and foliar-feeding insects in Plantago Lanceolata L. New Phytol 128:79-87
Gollotte A, van Tuinen D, Atkinson D (2004) Diversity of arbuscular mycorrhizal fungi colonising roots of the grass species Agrostis capillaris and Lolium perenne in a field experiment. Mycorrhiza 14:111-117

Gordon H, Haygarth PM, Bardgett RD (2008) Drying and rewetting effects on soil microbial community composition and nutrient leaching. Soil Biol Biochem 40:302-311

Gosling P, Ozaki A, Jones J, Turner M, Rayns F, Bending GD (2010) Organic management of tilled agricultural soils results in a rapid increase in colonisation potential and spore populations of arbuscular mycorrhizal fungi. Agric Ecosyst Environ 139:273-279

Goulding K, Jarvis S, Whitmore A (2008) Optimizing nutrient management for farm systems. Phil Trans R Soc B 363:667-680

Gustafson DJ, Casper BB (2004) Nutrient addition affects AM fungal performance and expression of plant/fungal feedback in three serpentine grasses. Plant Soil 259:9-17

Hartmann M, Widmer F (2008) Reliability for detecting composition and changes of microbial communities by TRFLP genetic profiling. FEMS Microbiol Ecol 63:249260

Hijri I, Sykorova Z, Oehl F, Ineichen K, Mäder P, Wiemken A, Redecker D (2006) Communities of arbuscular mycorrhizal fungi in arable soils are not necessarily low in diversity. Mol Ecol 15:2277-2289

Hoagland DR, Arnon DI (1950) The water-culture method for growing plants without soil. Calif Agric Exp Stn Circ 347:1-32

Hoeksema JD, Chaudhary VB, Gehring CA, Johnson NC, Karst J, Koide RT, Pringle A, Zabinski C, Bever JD, Moore JC, Wilson GWT, Klironomos JN, Umbanhowar J (2010) A meta-analysis of context-dependency in plant response to inoculation with mycorrhizal fungi. Ecol Lett 13:394-407

Hooper DU, Chapin FS, Ewel JJ, Hector A, Inchausti P, Lavorel S, Lawton JH, Lodge DM, Loreau M, Naeem S, Schmid B, Setala H, Symstad AJ, Vandermeer J, Wardle DA (2005) Effects of biodiversity on ecosystem functioning: a consensus of current knowledge. Ecol Monogr 75:3-35

Jakobsen I, Abbott LK, Robson AD (1992) External hyphae of vesicular-arbuscular mycorrhizal fungi associated with Trifolium subterraneum L. 1. Spread of hyphae and phosphorus inflow into the roots. New Phytol 120:371380

Johnson NC (1993) Can fertilization of soil select less mutualistic mycorrhizae? Ecol Appl 3:749-757

Johnson NC (2010) Resource stoichiometry elucidates the structure and function of arbuscular mycorrhizas across scales. New Phytol 185:631-647

Kardol P, Bezemer TM, van der Putten WH (2006) Temporal variation in plant-soil feedback controls succession. Ecol Lett 9:1080-1088

Kardol P, Cornips NJ, van Kempen MML, Bakx-Schotman JMT, van der Putten WH (2007) Microbe-mediated plantsoil feedback causes historical contingency effects in plant community assembly. Ecol Monogr 77:147-162

Kiers ET, West SA, Denison RF (2002) Mediating mutualisms: farm management practices and evolutionary changes in symbiont co-operation. J Appl Ecol 39:745-754 
Knacker T, van Gestel CAM, Jones SE, Soares A, Schallnass HJ, Forster B, Edwards CA (2004) Ring-testing and fieldvalidation of a Terrestrial Model Ecosystem (TME) - an instrument for testing potentially harmful substances: conceptual approach and study design. Ecotoxicology 13:9-27

Koide RT, Li M (1989) Appropriate controls for vesiculararbuscular mycorrhiza research. New Phytol 111:35-44

Kulmatiski A, Beard KH (2008) Decoupling plant-growth from land-use legacies in soil microbial communities. Soil Biol Biochem 40:1059-1068

Kulmatiski A, Beard KH, Stark JM (2006) Soil history as a primary control on plant invasion in abandoned agricultural fields. J Appl Ecol 43:868-876

Lendzemo VW, Kuyper TW, Kropff MJ, van Ast A (2005) Field inoculation with arbuscular mycorrhizal fungi reduces Striga hermonthica performance on cereal crops and has the potential to contribute to integrated Striga management. Field Crops Res 91:51-61

Liu RJ, Luo XS (1994) A new method to quantify inoculum potential of arbuscular mycorrhizal fungi. New Phytol 128:89-92

Mäder P, Fliessbach A, Dubois D, Gunst L, Fried P, Niggli U (2002) Soil fertility and biodiversity in organic farming. Science 296:1694-1697

McGonigle TP, Miller MH, Evans DG, Fairchild GL, Swan JA (1990) A new method which gives an objective measure of colonization of roots by vesicular arbuscular mycorrhizal fungi. New Phytol 115:495-501

Moonen AC, Bàrberi P (2008) Functional biodiversity: an agroecosystem approach. Agric Ecosyst Environ 127:7-21

Oehl F, Laczko E, Bogenrieder A, Stahr K, Bosch R, van der Heijden MGA, Sieverding E (2010) Soil type and land use intensity determine the composition of arbuscular mycorrhizal fungal communities. Soil Biol Biochem 42:724-738

Postma-Blaauw MB, de Goede RGM, Bloem J, Faber JH, Brussaard L (2010) Soil biota community structure and abundance under agricultural intensification and extensification. Ecology 91:460-473

Powell JR, Parrent JL, Hart MM, Klironomos JN, Rillig MC, Maherali H (2009) Phylogenetic trait conservatism and the evolution of functional trade-offs in arbuscular mycorrhizal fungi. Proc R Soc B 276:4237-4245

Power AG (2010) Ecosystem services and agriculture: tradeoffs and synergies. Phil Trans R Soc B 365:2959-2971

Reeve JR, Schadt CW, Carpenter-Boggs L, Kang S, Zhou J, Reganold JP (2010) Effects of soil type and farm management on soil ecological functional genes and microbial activities. ISME J 4:1099-1107

Rillig MC (2004) Arbuscular mycorrhizae and terrestrial ecosystem processes. Ecol Lett 7:740-754

Sanders IR (2010) 'Designer' mycorrhizas?: using natural genetic variation in AM fungi to increase plant growth. ISME J 4:1081-1083

Sawers RJH, Gutjahr C, Paszkowski U (2008) Cereal mycorrhiza: an ancient symbiosis in modern agriculture. Trends Plant Sci 13:93-97

Scheublin TR, van Logtestijn RSP, van der Heijden MGA (2007) Presence and identity of arbuscular mycorrhizal fungi influence competitive interactions between plant species. J Ecol 95:631-638
Smith SE, Read D (2008) Mycorrhizal symbiosis, 3rd edn. Academic, London

Smith FA, Grace EJ, Smith SE (2009) More than a carbon economy: nutrient trade and ecological sustainability in facultative arbuscular mycorrhizal symbioses. New Phytol 182:347-358

Sykorova Z, Ineichen K, Wiemken A, Redecker D (2007) The cultivation bias: different communities of arbuscular mycorrhizal fungi detected in roots from the field, from bait plants transplanted to the field, and from a greenhouse trap experiment. Mycorrhiza 18:1-14

Tilman D, Fargione J, Wolff B, D'Antonio C, Dobson A, Howarth R, Schindler D, Schlesinger WH, Simberloff D, Swackhamer D (2001) Forecasting agriculturally driven global environmental change. Science 292:281-284

Trouvelot S, van Tuinen D, Hijri M, Gianinazzi-Pearson V (1999) Visualization of ribosomal DNA loci in spore interphasic nuclei of glomalean fungi by fluorescence in situ hyhridization. Mycorrhiza 8:203-206

van der Heijden MGA (2010) Mycorrhizal fungi reduce nutrient loss from model grassland ecosystems. Ecology 91:1163-1171

van der Heijden MGA, Klironomos JN, Ursic M, Moutoglis P, Streitwolf-Engel R, Boller T, Wiemken A, Sanders IR (1998) Mycorrhizal fungal diversity determines plant biodiversity, ecosystem variability and productivity. Nature 396:69-72

van der Heijden MGA, Streitwolf-Engel R, Riedl R, Siegrist S, Neudecker A, Ineichen K, Boller T, Wiemken A, Sanders IR (2006) The mycorrhizal contribution to plant productivity, plant nutrition and soil structure in experimental grassland. New Phytol 172:739-752

van Diepeningen $\mathrm{AD}$, de Vos OJ, Korthals GW, van Bruggen AHC (2006) Effects of organic versus conventional management on chemical and biological parameters in agricultural soils. Appl Soil Ecol 31:120-135

van Tuinen D, Jacquot E, Zhao B, Gollotte A, Gianinazzi-Pearson V (1998) Characterization of root colonization profiles by a microcosm community of arbuscular mycorrhizal fungi using 25S rDNA-targeted nested PCR. Mol Ecol 7:879-887

Verbruggen E, Kiers ET (2010) Evolutionary ecology of mycorrhizal functional diversity in agricultural systems. Evol Appl 3:547-560

Verbruggen E, Röling WFM, Gamper HA, Kowalchuk GA, Verhoef HA, van der Heijden MGA (2010) Positive effects of organic farming on below-ground mutualists: largescale comparison of mycorrhizal fungal communities in agricultural soils. New Phytol 186:968-979

Wardle DA, Bardgett RD, Klironomos JN, Setala H, van der Putten WH, Wall DH (2004) Ecological linkages between aboveground and belowground biota. Science 304:1629-1633

Wilson GWT, Rice CW, Rillig MC, Springer A, Hartnett DC (2009) Soil aggregation and carbon sequestration are tightly correlated with the abundance of arbuscular mycorrhizal fungi: results from long-term field experiments. Ecol Lett 12:452-461

Yang YG, He ZL, Stoffella PJ, Yang XE, Graetz DA, Morris D (2008) Leaching behavior of phosphorus in sandy soils amended with organic material. Soil Sci 173:257-266

Zhu YG, Smith FA, Smith SE (2003) Phosphorus efficiencies and responses of barley (Hordeum vulgare L.) to arbuscular mycorrhizal fungi grown in highly calcareous soil. Mycorrhiza 13:93-100 